\title{
Did that Scare You? Tips on Creating Emotion in Experimental Subjects
}

\author{
Bethany Albertson \\ Department of Government, University of Texas, Austin, TX 78712 \\ e-mail: balberts@austin.utexas.edu \\ Shana Kushner Gadarian \\ Maxwell School of Citizenship and Public Affairs, Syracuse University, Syracuse, NY 13244 \\ e-mail: sgadaria@maxwell.syr.edu (corresponding author)
}

Edited by Justin Grimmer

\begin{abstract}
The appropriateness of experiments for studying causal mechanisms is well established. However, the ability of an experiment to isolate the effect of emotion has received less attention, and in this letter we lay out a guide to manipulating and tracing the impact of emotions. Some experimental manipulations are straightforward. Manipulating an emotion like anxiety is less obvious. There is no magic "political anxiety pill" and placebo that can be randomly assigned to participants. While the magic political anxiety pill is still elusive, we advocate using multiple manipulations, extensive pretesting, and mediation models. These approaches have allowed us to situate a discrete emotional experience in a complex political environment.
\end{abstract}

In recent decades, social scientists have turned their attention to emotion's role in a wide variety of phenomena such as voting (Abelson et al. 1982; Marcus, Neuman, and MacKuen 2000), candidate and presidential evaluations (Conover and Feldman 1986; Steenbergen and Ellis 2006), information processing (Redlawsk, Civinetti, and Lau 2007; Valentino et al. 2009), intergroup conflict (Halperin, Sharvit, and Gross 2011; Zeitzoff 2014), framing effects (Dillard et al. 1996; Huddy and Gunnthorsdottir 2000; Druckman and McDermott 2008), and public opinion (Kinder 1994; Brader 2006; Huddy, Feldman, and Cassese 2007; Huddy et al. 2003; Brader 2006; Brader, Valentino, and Suhay 2008). Increasingly, scholars are relying on experiments to trace the impact of emotions such as anxiety, anger, disgust, and enthusiasm on political life (see Groenendyk, Brader, and Valentino 2011 for a review). Experiments are well suited to trace the causal impact of a manipulation on a dependent variable, but for emotions, researchers need manipulations that will not only evoke the intended emotion, such as anxiety, but also isolate that emotion from other emotions (like anger) and isolate emotion from other processes such as cognition. In this letter, we lay out a guide to manipulating and tracing the impact of emotions based on our experience running more than a dozen experiments that test anxiety's effect on information seeking, trust, and public opinion.

Some experimental manipulations are straightforward. If we were studying attack advertising, we could randomly assign study participants to view an attack ad and measure the effects. We might think about what is the right control condition (should we show a positive ad, a neutral ad, or perhaps no political advertisement?), and we might consider how to present the advertisement (we might embed it in a television program, so that the goals of our study are less obvious and the viewing experience is more natural). We would have a number of judgment calls to make, but claiming that we manipulated our independent variable, exposure to an attack ad, would be relatively straightforward (at least in a laboratory or survey experiment design). Manipulating an emotion like anxiety is less obvious. There is no magic "political anxiety pill" and placebo that

Author's Note: Thank you to the participants at the West Coast Experiments Conference for feedback on an earlier version of this paper.

(C) The Author 2016. Published by Oxford University Press on behalf of the Society for Political Methodology.

All rights reserved. For Permissions, please email: journals.permissions@oup.com 
can be randomly assigned to participants, and we doubt that institutional research boards would be very enthusiastic about approving such a research design if it did exist. In lieu of a political anxiety pill, we recommend three strategies for studying emotions: (1) use multiple manipulations that approximate the effects of emotions in a variety of contexts, (2) use extensive pretesting to create effective emotion inductions, and (3) use mediation models to trace out the impact of the subsequent emotions on dependent variables of interest.

\section{Use Multiple Manipulations When Possible}

Experimental manipulations necessarily abstract away from some amount of political reality to test theory - we show subjects one campaign ad rather than the thousands that run during a campaign, we use behavioral games to capture trust and cooperation, we vary the language in a single public health issue rather than the universe of diseases. We suggest that experimentalists be sensitive to the set of political circumstances that they are approximating in their studies and potentially utilize more than one emotion manipulation if these manipulations will allow the researcher to test the effects of emotions under a variety of contexts. Table 1 outlines a variety of emotion manipulations and relevant databases. These manipulations range from apolitical inductions, such as biographical tasks that ask respondents to remember events or people that made them feel angry, anxious, or proud (Lerner and Keltner 2001; Valentino et al. 2009) to explicitly political stimuli, such as a negative ad with music and visuals manipulated to elicit emotion (Brader 2006). There is no perfect emotion manipulation - each has distinct strengths and weaknesses, and they can be used to complement each other.

Not every paper needs multiple studies and budgets are a constraint, but whatever manipulation the researcher uses should be used with an eye toward the political circumstances that it covers and what it does not. However, if researchers use several experiments to test theories, using more than one manipulation across these experiments has both theoretical and practical benefits. In our own work, we find the bottom-up manipulations, where respondents list their own worries and generate their own anxiety, have the broadest impact. When respondents generate their own worries about immigration, we find increased anxiety across partisan and racial groups. On the other hand, the impact of threatening immigration ads is constrained by the race and partisanship of the respondent. Had we only used bottom-up manipulations, we would have strong evidence that anxiety can override respondents' partisanship in how they form opinions and search for political information, but because we also use campaign manipulations, we are able to show that partisanship can act as a bulwark against anxiety when anxiety messages are overtly persuasive. Without both types of manipulations, we would know less about the universe of circumstances where anxiety may influence public opinion.

The theoretical benefit of using multiple manipulations is that it allows researchers to make broader claims about the circumstances in the world that moderate the effect of emotion, who in the public is most affected by what types of emotional experiences, and what the boundary conditions are when emotional appeals do not work. To the extent that researchers can use more than one type of manipulation (e.g., an evocative ad in one study and a biographical task in another), this will have a broader impact on theory because it will allow a test of the generalizability and robustness of the findings. As a practical matter, by showing when findings are sensitive to a particular type of context, multiple manipulations can help avoid publication bias. Rather than putting manipulations that "don't work" into a file drawer, by comparing the effects of multiple types of manipulations, we build a theory of the circumstances under which emotions matter, as well as incentivize the publication of null results. Budget-constrained researchers may be better off using bottom-up tasks since they are more universal (Searles and Mattes 2015), but as experimentalists, we learn something also about the limits of manipulations when we utilize more than one.

\section{Extensively Pretest Separate Elements of the Inductions}

Although it may seem like common sense advice, we think that it bears repeating that pretesting manipulations, particularly manipulations of subjective experiences, is a best practice and a necessary step. Experimenters should aim to pretest not only the main manipulation itself but also its constitutive parts. Researchers may utilize pretested images and sounds such as the ones in the 
Table 1 Examples of emotions manipulations

Type of manipulation

Examples and databases (if available)

Select other citations

Non political stimuli

Emotive faces

Flash subliminal faces prior to attitudinal questions (Erisen, Lodge, and Taber 2014)

Databases:

Ekman archive of facial expressions (Ekman and Friesen 1977)

CMU-Pittsburgh AU-Coded Face Expression Image Database (Kanade, Cohn, and Tian 2000)

Images (general) Respondents view images of man eating worms; emaciated body (disgust)

Database:

International Affective Picture System

(Lang, Bradley, and Cuthbert 1999)

Video clips

(non political)

Respondents watch relaxing clip about meditation (relaxation) or scene from movie "Cliffhanger" (anxiety) (Renshon, Lee, and Tingley 2015)

Database:

Archive of commercial films to elicit emotion (Gross and Levenson 1995) (http://spl.stanford.edu/pdfs/film.pdf)

Interpersonal

Respondents write an essay and receive feedback that is either neutral (control) or insulting (anger) (Harmon-Jones and Sigelman 2001)

Flexible stimuli (both political and apolitical versions exist)

Bottom-up, self-directed

"Please describe 3-5 things that make you angry [fearful]. Please describe in more detail the one situation that makes you the most angry so that someone reading will become angry." (Lerner and Keltner 2001)

"First, we'd like you to take a moment to think about the debate over immigration in the United States. When you think about immigration, what makes you worried? Please list everything that comes to mind."

(Gadarian and Albertson 2014)

Political stimuli News stories

Campaign ads

Vary language to be more/less threatening; emphasis on bad versus good economic news; instruct reader or listener to take the perspective of person in the story

Database:

Affective Norms for English Text (Bradley and Lang 2007)

Addition of threatening or hopeful visuals and music

Database (music):

International Affective Digitized Sounds (Bradley and Lang 1999)
(Banks and Valentino 2012; Chapman and Anderson 2013; Lodge and Taber 2013; Banks 2014; Zeitzoff 2014)

(Smith et al. 2011)

(Hubert and de Jong-Meyer 1991; Fredrickson and Branigan 2005; Rottenberg, Ray, and Gross 2007)

(Pedersen et al. 2008)

(Valentino et al. 2009)

(Batson et al. 2002; Brader, Valentino, and Suhay 2008; Gadarian 2010)

(Brader 2006; Albertson and Gadarian 2015) 
International Affective Picture Database (Lang, Bradley, and Cuthbert 2008) or databases of facial expressions (Ekman and Friesen 1978; Kanade, Cohn, and Tian 2000), but many scholars may want to create politically relevant manipulations such as campaign ads or news stories. For example, if a researcher chooses to use a newspaper article to deliver threatening news intended to create anxiety about immigration (Brader, Valentino, and Suhay 2008), this treatment may use both language and imagery as ways of creating anxiety, and both language and imagery should be pretested. The news portion could focus on the impact of immigration on the economy, cultural appeals about the English language, the effects on crime, or a combination of all three. Pretesting multiple versions of the news story with different policy areas, different amounts of evocative language, and even different headlines will make researchers more confident in choosing a story that evokes the most anxiety and the least amount of other emotions such anger, sadness, or enthusiasm. Pretests can also include questions measuring how much respondents learned from the stories and whether they found them interesting. Ideally, a pretest includes multiple candidates for each treatment and control, allowing the researcher to choose stories that vary only on their emotional content and not information level or interest. Images that are intended to make respondents feel anxious, angry, or disgusted should also be separately tested to pick images that vary only on the particular emotion but are not confounded with other dimensions such as vividness. ${ }^{1}$

In our own work on public health threats, we use newspaper stories about a smallpox outbreak to create anxiety in experimental subjects. Going into the study, we did two levels of pretesting: one set of pretesting to find a threatening infectious disease and a second set of pretesting to identify news stories that were equally informative but varied on how anxiety-producing they were. First, we constructed a list of nine diseases from the Centers for Disease Control and Prevention descriptions that were low salience, had vivid symptoms, and were believable enough to have outbreaks. We first did a small undergraduate convenience sample to ask people's familiarity with each condition, how serious they thought it was, and how anxious, reassured, angry, confident, or enthusiastic these nine diseases made them feel. As a second step, we then used the three diseases that created the most anxiety and were rated as most serious but low on familiarity to construct news stories. A key part of the experience of anxiety is uncertainty over future events (Lerner and Keltner 2001), but uncertainty can take a variety of forms. As a further check on what made something anxiety inducing, we varied the dimension of uncertainty in the different news stories-(1) time: an outbreak now versus in the past; (2) location: in the United States versus Canada; and (3) the population affected: cows versus humans. We used a 360-person convenience sample from Amazon's Mechanical Turk (Berinsky, Huber, and Lenz 2012) to pretest a set of six news stories constructed with the diseases identified in the first wave and one of the different ways to induce threat (time, location, population) and found that the smallpox stories that varied on the time of an outbreak produced the most anxiety overall and produced the most difference in levels of anxiety between the high and low threatening versions. Pretesting can be done quite inexpensively with convenience samples such as undergraduates or Mechanical Turk workers, though researchers should make sensible choices about which convenience sample is appropriate for a given study (Druckman and Kam 2011). For example, a relatively liberal undergraduate population is unlikely to share in the same immigration anxieties as a more representative American sample.

\section{Use Mediation Models}

The third methodological approach we take to establish the connection between anxiety and our dependent variables is the use of mediation models (Baron and Kenny 1986; Imai, Keele, and Tingley 2010). Extensive pretesting allows researchers to pick materials that are best suited to

\footnotetext{
${ }^{1}$ As one example, Brader, Valentino, and Suhay (2008) used two pictures of immigrants, one European, one Hispanic, in a news story to evoke anxiety about immigration while varying the salience of ethnic groups. In order to pick the images for the news story, they had eight judges rate forty photos on how European, Hispanic, wealthy, attractive, and law abiding they looked. After choosing two faces that were distinct only on ethnicity and no other traits, a graphic artist altered the images so that only the heads differed and the background, dress, etc., were identical.
} 
triggering anxiety and no other emotions, but of course picking good materials is not the same as picking perfect materials. It is also the case that emotions tend to co-occur (i.e., we feel both anxious and sad about a natural disaster), so even the most directed manipulation may still raise more than one emotion. Using the causal mediation approach advocated by Imai, Keele, and Tingley (2010) and Imai et al. (2011), researchers can test more directly that the manipulation, be it a news story, ad, or a piece of music, influences outcomes of interest through increasing the level of the intended emotion, not through increasing another emotion or through a non emotive mechanism (e.g., thinking). The mediation models explicated by Imai et al. (2011) come with a set of assumptions that the researcher must consider when designing and analyzing the experiment, including that the treatment is exogenous to the outcomes of interest and that the observed mediator is independent from the pretreatment and treatment confounders. To satisfy the statistical assumptions underlying this model, researchers must also include pretreatment variables that may be related to the dependent variable, as well as the emotional mediator (e.g., anxiety), in both the models predicting the mediator and the models predicting the outcomes of interest. The inclusion of pretreatment variables should be driven by the literature on the antecedents of the discrete emotion, as well the particular policy area that experimenters are testing. Measures of personality, such as need for affect and need for cognition (Arceneaux and Vander Wielen 2013) and risk tolerance (Berinsky and Lewis 2007; Kam and Simas 2010), or scales for specific emotions, such as a disgust sensitivity scale (Haidt, McCauley, and Rozin 1994), can be good choices to include on the survey instrument since they predict both emotions and attitudes. Other individual political differences such as gender, education, ideology, and partisanship are likely to shape outcomes such as voting, opinion, and information seeking across multiple policy areas and potential emotional reactions, so they are also good choices for inclusion as pretreatment variables. We also recommend including measures of emotional reactions after exposure to the treatment to both confirm that the chosen, pretested manipulation works as expected in the main sample and allow for use in the mediation models.

When experimental treatments may potentially affect multiple mediators, as is the case when treatments can raise both anxiety and anger or other combinations of emotions, this may pose challenges to inference (Bullock, Green, and Ha 2010; Imai et al. 2011). But even in these challenging cases there are statistical tools available (Imai and Yamamoto 2013). By measuring multiple emotions after the treatment, researchers can model the impact of more than one emotion, as well as run sensitivity analyses as suggested by Imai and Yamamoto (2013) and Imai et al. (2011). Careful pretesting should lead to more successful manipulations of emotion, and theory building should lead researchers to both consider alternative mediators and plan how to code for and test those potential mediators. For example, in our own work testing the impact of immigration anxiety on information seeking, we wanted to rule out the possibility that it was salience of immigration or anger about immigration that led respondents to seek threatening immigration news, rather than anxiety. To test these alternatives, we had research assistants unaware of our hypotheses and the experimental treatment code the open-ended thought-listing manipulation to measure the level of anxiety expressed by each respondent. The research assistants coded for the number of worries expressed as well as the intensity of anxiety, anger, and enthusiasm expressed by each respondent. Additionally, coders counted the number of words used as a measure of thinking, which allowed us to rule out cognition as an alternative mediator.

Although the magic political anxiety pill is still elusive, we advocate using multiple manipulations, extensive pretesting, and mediation models. These approaches have allowed us to situate a discrete emotional experience in a complex political environment.

\section{Funding}

Time Sharing Experiments in the Social Sciences, a National Science Foundation infrastructure program (TESS grant in 2007, Diana Mutz and Arthur Lupia, Co-PIs; TESS grant in 2011, James Druckman and Jeremy Freese, Co-PIs). Institutional review board (IRB) approval received for Immigration KN Study 2007 granted by Princeton University and University of Washington, and 
IRB approval for Public Health-Smallpox Study 2011 and Immigration KN Study 2011 granted by the University of California-Berkeley and the University of Texas-Austin.

\section{Conflict of interest statement. None declared.}

\section{References}

Abelson, Robert, Donald Kinder, Mark D. Peters, and Susan Fiske. 1982. Affective and semantic components in political person perception. Journal of Personality and Social Psychology 42(4):619-30.

Albertson, Bethany, and Shana Kushner Gadarian. 2015. Anxious politics: Democratic citizenship in a threatening world. New York: Cambridge University Press.

Arceneaux, Kevin, and Ryan J. Vander Wielen. 2013. The effects of need for cognition and need for affect on partisan evaluations. Political Psychology 34(1):23-42.

Banks, Antoine J. 2014. Anger and racial politics: the emotional foundation of racial attitudes in America. New York: Cambridge University Press. http://www.cambridge.org/us/academic/subjects/sociology/political-sociology/anger-andracial-politics-emotional-foundation-racial-attitudes-america.

Banks, Antoine J., and Nicholas A. Valentino. 2012. Emotional substrates of white racial attitudes. American Journal of Political Science 56(2):286-97.

Baron, R., and David Kenny. 1986. The moderator-mediator variable distinction in social psychological research: Conceptual, strategic, and statistical considerations. Journal of Personality and Social Psychology 51:1173-82.

Batson, C. Daniel, Johee Chang, Ryan Orr, and Jennifer Rowland. 2002. Empathy, attitudes, and action: Can feeling for a member of a stigmatized group motivate one to help the group? Personality and Social Psychology Bulletin 28(12):1656-66.

Berinsky, Adam, Gregory A. Huber, and Gabriel S. Lenz. 2012. Evaluating online labor markets for experimental research: Amazon.com's mechanical turk. Political Analysis 20(3):351-68.

Berinsky, Adam, and Jeffrey B. Lewis. 2007. An estimate of risk aversion in the U.S. electorate. Quarterly Journal of Political Science 2(2):139-54.

Brader, Ted. 2006. Campaigning for hearts and minds: How emotional appeals in political ads work. Studies in communication, media, and public opinion. Chicago: University of Chicago Press.

Brader, Ted, Nicholas A. Valentino, and Elizabeth Suhay. 2008. What triggers public opposition to immigration? Anxiety, group cues, and immigration threat. American Journal of Political Science 52(4):959-78.

Bradley, Margaret M., and Peter J. Lang. 1999. International affective digitized sounds (IADS): stimuli, instruction manual and affective ratings. Technical Report No. B-2. Gainesville, FL: The Center for Research in Psychophysiology, University of Florida.

. 2007. Affective norms for English text (ANET): affective ratings of text and instruction manual. Technical Report No. D-1. Gainesville, FL: University of Florida.

Bullock, John G., Donald P. Green, and Shang E. Ha. 2010. Yes, but what's the mechanism? (Don't expect an easy answer). Journal of Personality and Social Psychology 98(4):550-58.

Chapman, Hanah A., and Adam K. Anderson. 2013. Things rank and gross in nature: A review and synthesis of moral disgust. Psychological Bulletin 139(2):300-27.

Conover, Pamela Johnston, and Stanley Feldman. 1986. Emotional reactions to the economy: I'm mad as hell and I'm not going to take it anymore. American Journal of Political Science 30(1):50-78.

Dillard, James Price, Courtney Plotnick, Linda Godbold, Vicki Freimuth, and Timothy Edgar. 1996. The multiple affective outcomes of AIDS PSAs: Fear appeals do more than scare people. Communication Research 23(1):44-72.

Druckman, James, and Cindy Kam. 2011. Students as experimental participants: A defense of the 'narrow data base.' In Cambridge handbook of experimental political science, eds. James Druckman, Donald Green, James Kuklinski, and Arthur Lupia, 41-57. New York: Cambridge University Press.

Druckman, James, and Rose McDermott. 2008. Emotion and the framing of risky choice. Political Behavior 30(3):297-321.

Ekman, P., and W.V. Friesen. 1977. Nonverbal Behavior. In Communication and Social Interaction, ed. P.F. Ostwald, $37-$ 46. New York: Grune \& Stratton.

Ekman, Paul, and Wallace Friesen. 1978. Facial action coding system: a technique for the measurement of facial movement. Palo Alto, CA: Consulting Psychologists Press.

Erisen, Cengiz, Milton Lodge, and Charles S. Taber. 2014. Affective contagion in effortful political thinking. Political Psychology 35(2):187-206.

Fredrickson, Barbara L., and Christine Branigan. 2005. Positive emotions broaden the scope of attention and thoughtaction repertoires. Cognition and Emotion 19(3):313-32.

Gadarian, Shana Kushner. 2010. The politics of threat: How terrorism news shapes foreign policy attitudes. Journal of Politics 72(2):1-15.

Gadarian, Shana Kushner, and Bethany Albertson. 2014. Anxiety, immigration, and the search for information. Political Psychology 35(2):133-164.

Groenendyk, Eric, Ted Brader, and Nicholas Valentino. 2011. Appraising political emotions: Appraisals, emotions, and behavior in response to threatening news. Unpublished paper, University of Memphis.

Gross, James, and Robert Levenson. 1995. Emotion elicitation using films. Cognition and Emotion 9(1):87-108. 
Haidt, Jonathan, Clark McCauley, and Paul Rozin. 1994. Individual differences in sensitivity to disgust: A scale sampling seven domains of disgust elicitors. Personality and Individual Differences 16(5):701-13.

Halperin, Eran, Keren Sharvit, and James Gross. 2011. Emotion and emotion regulation in intergroup conflict: An appraisal based framework. In Intergroup conflicts and their resolution: Social psychological perspective, ed. Daniel Bar-Tal, 83-104. New York: Psychology Press.

Harmon-Jones, E., and J. Sigelman. 2001. State anger and prefrontal brain activity: Evidence that insult-related relative left-prefrontal activation is associated with experienced anger and aggression. Journal of Personality and Social Psychology 80(5):797-803.

Hubert, W., and R. de Jong-Meyer. 1991. Autonomic, neuroendocrine, and subjective responses to emotion-inducing film stimuli. International Journal of Psychophysiology: Official Journal of the International Organization of Psychophysiology 11(2):131-40.

Huddy, Leonie, Stanley Feldman, and Erin Cassese. 2007. On the distinct political effects of anxiety and anger. In The affect effect: Dynamics of emotion in political thinking and behavior, eds. W. Russell Neuman, George E. Marcus, Ann N. Crigler, and Michael MacKuen, 202-30. Chicago: University of Chicago Press.

Huddy, Leonie, Stanley Feldman, Gallya Lahav, and Charles S. Taber. 2003. Fear and terrorism: Psychological reactions to 9/11. In Framing terrorism: The news media, the government, and the public, eds. Pippa Norris, Montague Kern, and Marion R. Just, 255-280. New York: Routledge.

Huddy, Leonie, and Anna Gunnthorsdottir. 2000. The political effects of emotional imagery: Superficial manipulation or a deepening conviction? Political Psychology 21(4):745-78.

Imai, Kosuke, Luke Keele, and Dustin Tingley. 2010. A general approach to causal mediation analysis. Psychological Methods 15(4):309-34.

Imai, Kosuke, Luke Keele, Dustin Tingley, and Teppei Yamamoto. 2011. Unpacking the black box of causality: Learning about causal mechanisms from experimental and observational studies. American Political Science Review 105(4):765-89.

Imai, Kosuke, and Teppei Yamamoto. 2013. Identification and sensitivity analysis for multiple causal mechanisms: Revisiting evidence from framing experiments. Political Analysis 21(2):141-71.

Kam, Cindy, and Elizabeth Simas. 2010. Risk orientations and policy frames. Journal of Politics 72(2):381-96.

Kanade, Takeo, Jeffrey F. Cohn, and Yingli Tian. 2000. Comprehensive database for facial expression analysis. In Proceedings of the fourth IEEE international conference on automatic face and gesture recognition, 484-90. Grenoble, France.

Kinder, Donald. 1994. Reason and emotion in American political life. In Beliefs, reasoning, and decision making: Psychologic in honor of Bob Abelson, eds. Robert Schank and Ellen Langer, 277-314. Hillsdale, NJ: Lawrence Elbaum.

Lang, P. J., Margaret M. Bradley, and B. N. Cuthbert. 2008. International affective picture system (IAPS): Affective ratings of pictures and instruction manual. Technical Report A-8. Gainesville, FL: University of Florida.

Lerner, Jennifer S., and Dacher Keltner. 2001. Personality processes and individual differences - fear, anger, and risk. Journal of Personality and Social Psychology 81(1):146.

Lodge, Milton, and Charles S. Taber. 2013. The rationalizing voter. New York: Cambridge University Press. http://www. cambridge.org/us/academic/subjects/politics-international-relations/politics-general-interest/rationalizing-voter.

Marcus, George, W. Russell Neuman, and Michael MacKuen. 2000. Affective intelligence and political judgment. Chicago: University of Chicago Press.

Pedersen, William C., Brad J. Bushman, Eduardo A. Vasquez, and Norman Miller. 2008. Kicking the (barking) dog effect: The moderating role of target attributes on triggered displaced aggression. Personality and Social Psychology Bulletin 34(10):1382-95.

Redlawsk, David P., Andrew J. W. Civinetti, and Richard R. Lau. 2007. Affective intelligence and voting: information processing and learning in a campaign. In The affect effect: Dynamics of emotion in political thinking and behavior, eds. W. Russell Neuman, George E. Marcus, Ann N. Crigler, and Michael MacKuen, 152-79. Chicago: University of Chicago Press.

Renshon, Jonathan, Jooa Julia Lee, and Dustin Tingley. 2015. Physiological arousal and political beliefs. Political Psychology 36(5):569-585.

Rottenberg, J., R. D. Ray, and J. J. Gross. 2007. Emotion elicitation using films. In The handbook of emotion elicitation and assessment, eds. James A. Coan, and John J.B. Allen, 9-28. London: Oxford University Press.

Searles, Kathleen, and Kyle Mattes. 2015. It's a mad, mad world: Using emotion inductions in a survey. Journal of Experimental Political Science FirstView (April):1-11.

Smith, Kevin, Douglas Oxley, Matthew Hibbing, John Alford, and John Hibbing. 2011. Disgust Sensitivity and the Neurophysiology of Left-Right Political Orientations. PLoS One. 6(10): e25552. doi: 10.1371/journal.pone.0025552.

Steenbergen, Marco, and Christopher Ellis. 2006. Fear and loathing in American elections: Context, traits, and negative candidate affect. In Feeling politics: Emotion in political information processing, ed. David P. Redlawsk, 109-34. New York: Palgrave Macmillan.

Valentino, Nicholas A., Antoine Banks, Vincent Hutchings, and Anne K. Davis. 2009. Selective exposure in the internet age: The interaction between anxiety and information utility. Political Psychology 30(4):591-613.

Zeitzoff, Thomas. 2014. Anger, exposure to violence, and intragroup conflict: A 'lab in the field' experiment in southern Israel. Political Psychology 35(3):309-35. 